\title{
An Introduction to the Theory of a State-Paper Catalogue.
}

IN order to render the State-Papers of any country properly available to the student, there are three indispensable preliminaries, which it is well to mention here.

The first is an Anrual List of Stats-Papers arranged under the Departments by which they are issued. The second is an Annual Report on the State-Papers entered in the Lists, dealing with the system of compilation, the relative use, and the contents of the more important Reports. The third is a State-Paper Catalogue.

The first two subjects I shall hope to deal with on a future occasion, and the third is too large a subject to be quickly scrambled over. I shall confine myself, therefore, to-day to a few remarks introductory to the Theory of a State-Paper Catalogue.

I feel that no excuse is needed for my choice of subject, and that it is quite unnecessary, before such an audience, to dilate upon the intrinsic value of State-Papers. No one can have paid the slightest attention to the class of works in question and be ignorant of the existence of numberless reports of the greatest value, not only on such subjects as are obviously matters of Government Administration, but upon those branches of science, literature, and art, which are too commonly supposed to be matters of private enterprise alone. But if librarians have a knowledge of such matters, the same can scarcely be said of the outside public, for the ignorance which is generally displayed on the subject is truly deplorable, and must have been noticed by us on many occasions.

In regard to British State-Papers for instance; there seems to be an idea generally prevalent that all English State-Papers consist of dry statistics-a strange fancy, but, I believe, in no \footnotetext{
1890.

' Read at the Annual Meeting of the Library Association, Reading, September,
} 
way exaggerated. It would seem as if the average Englishman argued thus:-Statistics are issued as "Blue Books." All English State-Papers appear in Blue Books; therefore all StatePapers consist solely of dry statistics.

We find that similar prejudices exist in other countries, and the natural result is that reports worthy to be read of hundreds of thousands are read by tens of hundreds, and reports of worldwide interest and value have a circulation little wider than the shelves of connected departments.

Let us take the case of America. What general knowledge shall we find concerning the existence of the splendid publications of the Smithsonian Institution with its connected Departments, or concerning the reports of the Bureau of Education, the Agricultural Department, the Census Reports, or those of the numerous Surveys?

In regard to India: What genoral knowledge shall we find concerning the contents of the Indian Scientific Surveys, the Archæological Surveys, or the large body of interesting reports of an historical or geographical nature, apart from reports of numerous other departments, which testify to the wondrous administration of a wondrous empire?

Or if we turn to France: What goneral knowledge shall we find concerning the vast store of valuable science and art documents which have been issued by the French Minister of Public Instruction and by other departments? The answer must be, I fear, in every case, unsatisfactory.

The question which naturally suggests itself then to our minds is this:-What have Librarians done to dispel existing illusion and prejudice on the subject, and to enlighten the popular ignorance?

And although I would willingly plead a defence of my own craft, I fear I can give no very satisfactory answer. It is true we cannot force an unwilling horse to drink, but, have we led him to the water?

If we turn to the more prominent countries it is in vain that we seek for a comprehensive catalogue which fulfils the conditions requisite in a State-Paper Catalogue. And here let me anticipate a shower of contradictions by shielding myself behind a definition, viz., by stating what are the conditions demanded in the compilation of such a work.

Firstly: a State-Paper Catatogues should consist exclusivaly of official State-Papers. This is the first condition, and yet the one 
which is most often violated. It is a wrong principle to $\mathrm{mix}$ known and unknown factors together, for the natural result is that the insertion of the one cancels the certainty of the other, and renders the whole imperfect. Now State-Papers are known factors. Anyone who has the slightest knowledge of the system of Administration obtaining in a country can say with certainty that such and such reports should be found, even though he may never have seen them or heard mention of their existence. And if such State-Papers be kept separate by themselves, it is possible eventually to render them accessible to the public in a satisfactory manner.

Compared with State-Papers, however, all other works are practically uncertain factors. You never know what proportion of works on a given subject you may expect to find in a catalogue. You probably are ignorant of the different views which dictate them, while the principles which govern the cataloguing of the one clash with those which control the other, and confusion is the natural result.

Secondly: A State-Paper Catalogus should be a Continuous Catalogwe, from the earliest date onwards. And this necessarily implies that the volumes shall not be bound up annually according to Years, but according to Subjects.

For some purposes it may be quite right to have StatePapers bound up according to the Year, but from the point of view in question it is absolutely wrong. Thus, in the case where you wish to consult reports on Public Instruction for the last twenty years. According to the axrwal system of binding you would have to consult twonty different indexes, and from twonty different shelves you would have twenty different volumes brought you, each containing in addition fifty or 100 reports which you do not want (and where pagination is often absent we know it is no easy task to find one report out of roo others).

In cases where Ten-Year indexes are published, you would of course only have to consult two indexes, but my subsequent remarks would still hold good. Contrast on the other hand the facilities afforded by the system of Subject-binding. You wish for the reports of twenty years. All you have to do is to look at one entry in one catalogue, and you have your reports brought to you in a brief moment, from ons shelf, and contained probably in ons volume (or certainly in not more than five volumes). These illustrations are sufficient to prove the merits of the one system and the defects of the other. 
Thirdly: the title should generally be extered in full, as far as is necessary adequately to express the contents of the volume, and to enable you to identify a report with ease. Here, again, we see the advantages of the system of binding by subjects, for the result of binding by years is to encourage indexes to the exclusion of catalogurs, and indexes will never present the same number of titles with the same fulness as catalogues would. In fine, a State-Paper Catalogue should be compiled in such a manner that a student can find any given report, or collection of connected reports (from the earliest date onwards), described under the department or subject concerned, subordinate to the country to which the reports relate. These are the main essentials. But I find that my definition is imperfect, for $I$ have omitted to define the term "State-Paper." And indeed it is not easy to define it in a moment; for although we know that State-Papers form a class distinct by themselves, it is not always easy to assign the limits, for at this point we have to take into consideration the different forms of Government in various countries, and judge each on its own merits

This is not the time, however, to purswe such an inquiry, and, therefore, we shall confine ourselves to the general statement that State-Papers are those Reports which are published by the Supreme Goormment of a State or Collection of States, or by the direct Representatives of the Supreme Gooornment.

India furnishes us with a good example of a Supreme Government, with separate subordinate Provincial Governments. The United States, of course, supply another similar example. But what about the new phenomena of Local Government in the form of County Councils or Municipal Bodies, if they publish Reports of Proceedings?

For answer, we refer back to our definition of "State-Papers." Is the County Council the direct representative of the Supreme Government ? In effect: is the Local Government a miniature Supreme Government, conducting all the ordinary branches of the Imperial Administration only on a Provincial scale?

The answer is in the negative. The County Council is a representative, but not the representative of the Supreme Government. Equally so in the case of English Municipal Government.

For these reasons, therefore, it seems right to exclude this class of works from the general body of a State-Paper Catalogue, although there would be no harm if they were included as an Appendix. 
Finally, in regard to Semi-official papers (as also in the case of a certain class of Official Reports relating to Science and Art), we have no option but to catalogue them in duplicate, that is to say, both in the State-Paper Catalogue, and also in the General Catalogue, the only possible alternative being in those cases where it may be found advisable to omit them as main-titles in the one and make instead copious general crossreferences or notes to the other.

Bearing in mind then our definition of State-Papers, and the conditions to be fulfilled by a State-Paper Catalogue, I am afraid that our search will be fruitless.

We most of us know that in I885 the U.S. Government published a work which is a marvel of perseverance and industry, entitled: $A$ Descriptive. Catalogwe of the Govormment Publications of the United States ... 1774 ... 188r. Compiled [under the directions of a foint Committee on Printing] . . . by B. P. Poore - 1885, fal. But apart from the descriptive matter, it is only a chronological Registor, with an Index of Matters at the end, and would stand no comparison with a properly compiled Catalogue of the same papers arranged according to Departments and Subjects. Thus, if we wished to know what are the published works of the U.S. Geological and Geographical Surveys up to $188 \mathrm{r}$, we should look in the Index of Matters, and be referred to fifty-five different pages. Now the catch-words, or catch-sentences, under which the separate titles are entered, are so unsatisfactory that one has frequently to scan the whole page, certainly once, if not more times, in order to find a required entry, and since the average number of titleentries on the first two and last two pages referred to is fifty a page, according to this estimate, in order to view fifty-five different entries desired, we might have to scan the greater part of $55 \times 50$, or 2,750 different entries in order to find the 55 required, and under extreme circumstances we might have to scan a couple of thousand entries in order to find one single work alone.

As a matter of fact, in the particular instance just noted, there are Departmental lists of these identical publications mentioned. But a State Catalogue which has to rely upon Departmental catalogues which are often not forthcoming, is not worthy of the name of a catalogue, and a system which admits of such complications is assuredly no system to encourage.

Apart from the above criticism, the titles in this catalogue are not always full or literal, which is a fact also to be lamented. 
Before I pass from America, however, I should mention that an enterprising publisher at Washington, Mr. Lowdermilk, is making meritorious efforts in connection with the cataloguing of U.S.A. State-Papers on a more practical basis, and we must wish him every success in his undertaking.

Mr. J. H. Hickcox, also of Washington, has published for some time a monthly catalogue of U.S. Official Publications.

If we turn to India, we shall come across certain Catalogues issued by the Government of India, and a Catalogue of the Documents in the Marine Survey Office at Calcutta, by Mr. Carrington; also a Catalogue of the Library of the Indian Museum.

Next we shall find the Catalogue of the India Office Library, and the valuable Catalogues of the India Surveys Maps and Charts which have been published. But these are all Dopartmental works.

I am told that the Austrian Government once published a very complete list or catalogue of Austrian State-Papers, but I have never been able to obtain a copy, so as to be able to judge of its character.

In England, it is true, we have, in the Official annual printed Indexes to the Parliamentary Papers, the next best substitutes for a continuous State-Paper catalogue, but, as before stated, such indexes are accompanied by great disadvantages. I should mention, however, that Mr. Dorset Eccles, while in charge of the Newspaper Reading Room at the British Museum, commenced an annual Card Index to the English Parliamentary Papers, the accessions of each year being afterwards incorporated with those of previous years, dating from 1885 , and that the Index referred to has been most useful, both for reference while the official index is in progress of compilation, and also as a Supplementary Index.

In France, Hachette publishes Lists of French State-Papers, as Spottiswoode does in England, but from their very nature these lists must be of a periodical character. I think, therefore, I have reason when I say that there is a great want of continuous State-Paper Catalogues.

But supposing that we wished to compile such a catalogue, how should we set about it? On what principles should we compile it? And with this question we plunge into the theory of the subject.

Given a country and a mass of State-Papers to catalogue. 
Now in order to appreciate the significance and the relative value of the numerous factors with which we have to deal, it will be necessary to commence from the very beginning.

We start, then, with two main factors: I. The Life of a Country (consisting of facts and groups of facts, mostly connected in greater or less degree), and II. The Government which controls that Lifo (as shown in the method of Government, in the method of compiling Records of that Government, and in the method of publishing those compiled Records).

We find, then, that the ideal Theory of Publication is dependent (a) on the actual occurrence of facts according as they are more or less intricate in their connection with one another (b), as also upon the mode of treating those facts pursued by the Government, as shown in the organisation and functions of departments $(c)$, as also upon the manner in which the Records of Government are compiled (d), as also upon the manner in which the compiled Records are published.

Thus, if the facts in question exist in simple or well-defined connection with one another, or with the whole, and the mode of treatment, i.e., the system of Administration, be logical and simple, and the manner of compiling the reports be logical with itself, or in harmony with the principles of Catalogue-Classification, and the subsequent stages of publishing the reports (including binding), be reasonable and logical, then the cataloguer's difficulties would be imaginary, and all the stores of official wisdom would be made accessible to the public as with a stroke of the magician's wand.

But-and here commence our difficulties-it is needless to say that such a convenient arrangement never exists. There are few countries which have not their share of tangled and intricate institutions-the growth of ages. Assuredly there can be no country in which we can find absolute and permanent harmony between the several Departments and the subjects entrusted to their charge. There is no country in which the system of Departmental Classification necessarily harmonizes with the system required to be adopted in the case of a State-Paper Catalogue; and there are no countries which we can hold up as examples in their adherence to correct principles of Compilation and Publication. In the case of India, for example, it is obvious that no system of departmental organisation and reporting could be very simple, where it has to cvolve order out of so many varied systems of Law, with corres- 
ponding numbers of Law Courts. Similar and partly connected complications appear in connection with the numerous Land Revenue systems obtaining in different portions of India, while, as regards illogical connection of subject and department, and subsequent error in matters of compilation and publication, any general illustrations of any special country would be superfluous.

Realising then the nature of the difficulties which we may expect to encounter, it is most essential that we should get a clear idea of the particular principles which we should follow, in order that, when in cataloguing, we meet with other principles which are at variance with our special object, or encounter violations of the general principles of Classification, we shall be able to detect where the divergences occur, and be in a position to counteract the bad effects so far as is possible.

First of all, then, it is most important to note (as we have hinted before) that the principles of subject grouping in regard to a State-Paper Catalogue are not necessarily the same (as is too commonly supposed) as those which affect the grouping of Subjects under a department, and consequently influence the compilation of departmental reports.

All classification naturally depends upon the particular object desired. Thus the Dopartmont will classify its facts in order to facilitate its own particular ends in view (often a matter of expediency rather than of desire).

In the Gercoral Administration Report of a Province, depart. ments and subjects will be re-classified according to a method best calculated to meet the requirements of a Review of Provincial Administration.

The India Offec (in its report on the Moral and Material Progress of India) will re-classify subjects and departments on a broader basis as suffices for a bird's-eye view of the Administration of all India.

And similarly the Cataloguer of State-Papors re-classifies subjects and groups in order to fulfil the special object which he has in view. Now we have already defined that object, but it will be convenient to repeat it.

Given a country, our general object is so to group the subjects of our country as best to facilitate reference to reports written on those subjects; or, to put it more in detail (as before stated), so to arrange our groups that any student may be able speedily to ascertain what reports, from the earliest date onwards, have been published on any Subject-Group, or on any part of 
that Group, and find any such reports entered under the country to which they relate.

We say, then, that there are in our country a certain number of Groups of subjects (liable, of course, to increase) for which separate reports may reasonably be expected to be found. We therefore single out these most central subjects, with their parts in the Administration of the country, and endeavour so to manipulate them as to make each group exclusive of every other group. But this we find to be impossible, for we find that certain groups regarded as "whotes" are connected with one another, and that even where the groups, as groups, are mainly unconnected, that there are often certain factors which are common to many groups, sometimes in definits relationship, at others in irdefinits relationship to them.

Thus in India the groups of Agriculture, Land Surooys (Trigonownetrical, Topographicol and Revorus) and Land Settlements may generally be considered as separate groups, but they are very closely connected, and are, or have been, often reported upon in common.

As a further illustration of the manner in which a subject will enter into numerous groups in definite relationship we may mention Meteorology, which necessarily enters into the composition of India Administration as much as it does unnecessarily into English conversation. Thus, apart from standing as a group by itself in the light of a Meteorological Department, it enters subordinately into the composition of the following groups :-

Agriculture.

Arboriculture.

Finarcial Administration.

Forestry.

Irrigation and Navigation.

Land Reocisus Adurinistration.

Land Rovente Settlemest Dept.

Products.

Public Works Dept.

Post Ofico Dopt.

Rovenus Administration.

Sasitation (Military and Cioil).

Tetegraph Dopt.

Trado.

In fact it is obvious that the state of the weather may affect any group besides the ones especially mentioned. 
Again, as regards a subject being common to many groups with ixdefinite relations to them, we have only to mention Indian History and Geography (taken together). Now if anyone wished to peruse all that has been written on the subject of the past history of the Indian people, including their manners and customs, legends and lore, and on the physical features of the country, he would at the very least have to peruse the reports on the following subject groups or their subdivisions.

Firstly, those reports which relate avowedly to the subject, $8 . g .:-$

Archeological Roports.

Gasettoors.

Geographical Travels and Expeditions Reports.

Historical, Geographical and Statistical Reports and the Records Commission Roports.

Secondly: he would have to scan the pages of the Gowcral Administration Reports, as also of reports relating to such diverse subjects as-

Consusas.

Language.

Military Expeditions.

Palitical Missions.

Routas.

Talograph Administration.

Land Revenus.

Land Reoowne Suroey and Settloment or Land Racords, Agriculture and Sattlement Roports of cach Province, and also the Reports on the Great Swrocys of India, Revemu, Trigomonatrical and Topographical.

Every one of the above subject groups reports will often contain identically the same information in regard to this broad subject of history and geography. Since, therefore, we cannot arrive at absolute exclusiveness of all the groups, we have to content ourselves with the nearest approach to it, and we therefore arrange our groups in such a way that each group can assert prior claim if not sole claim to all its parts. And in illustration of this principle we cannot do better than quote $\mathbf{M r}$. Clements Markham's words in regard to the sectional arrangement of the Moral and Material Progress Reports of India, where he says that each section treats "of a special administrative subject or group of subjects, the aim being to include in each section those subjects which have more characteristics in common with one another [for the purpose in question] than 
any of them have in common with any other report not in that section."

Now although Mr. Markham enunciates this general principle in special reference to the object of an Annual Review of Indian Administration, the general principle applies equally to all species of classification, whatever the object may be, and thus to the grouping of subjects for the purpose of a StatePaper Catalogue.

We have now arranged our different Subject-groups, and have called them each by the name which is calculated most clearly and accurately and yet comprehensively, to designate the contents. But we do not bind ourselves to keep to these groups, for fresh principles now come into operation in connection with the extent and composition of each group and otherwise.

Thus, if our groups are large ones, and we find that there are series within series contained in them, we should proceed to subdivide them; but we must be cautious in 80 doing. For while Over-centralisation is an evil, so also is an excess of Decentralisation. If we omit to subdivide large groups which admit of clearly-defined groups being further extracted from them, the result will be an unsatisfactory vagueness, which renders it less easy to trace the several parts. If, on the other hand, we split up our groups too much, we are in danger of losing count of the numerous scattered fragments, and of having to scour the whole Catalogue in different directions in order to discover their existence.

Our golden rule then is this: Avoid the two extremes of excessive Concentration or Separation, and be sure that your groups, even if they are not absolutely exclwsive of ons another, are at heast ctearly defined.

In accordance with the above principles we shall hold ourselves at liberty, if necessary, to split up any one group into two or more sections, ${ }^{*}(a)$ either retaining those sections under the group, or separating them, $(b)$ and raising them to the rank of groups, each under its own designation. (We should take care, however, that there be connecting General cross-references between the separated parts, unless the connection be obvious.)

But even yet we have not finished enumerating the different possible modifications of our Group-arrangement. Instances occur where an important subject, which has a standing of its own, is found attáched to a group which has direct claims

- For examples of (a)-(e) See Appendix, 
upon it, but not exclusioe claims. In such an instance (c) we should sever the attachment, and raise the part to the rank of a group-taking care, however, as in the previous instance, to show the connection between the two.

Furthermore, if any case (d) arose in which no group existed for a new part come to light, we should enter that single part separately as if it were a group. Geographical considerations (o) will often necessitate other modifications, when we have to deal with subjects which cross the provinces of a country, such as Railways, Rivers, Canals, or Mountains.

These are the more common cases, which may necessitate interference with our imaginary Group-arrangement. And they are sufficient to show that we must not expect to find any one relationship of group to group, but all three relationships of "Sub-ordination, Super-ordination, and Co-ordination," and sometimes, as already hinted, No-ordination. And now to proceed with our theory.

Having settled our groups on a broad basis, and re-settled them according as subsequent circumstances demand, and having pointed out the possible relationships between them, it remains for us to base the compilation of our reports upon those groups as much as possible.

We have stated before that the Theory of Departmental classification is not necessarily in harmony with the system of the Cataloguer. It follows naturally that the Record of those classified Facts may be at variance with the Cataloguer's ideal system of Compilation.

Thus, in regard to Compilation, we may take it that, from a departmental view, so long as a report contains an accurate and logical record of facts in accordance with the main object of the record, other matter may be included (either for convenience or of necessity) which may have nothing directly to do with the real subject of the Report. While in regard to Publication, so far as the purposes of Departmental Administration are concerned, it is sufficient to affix a name which shall accurately express the main object or the general contents of a report, without immediate reference to other publications on the subject. Thus, in such instances Compilation is not necessarily carried out with any special regard to future Publication, Publication being perhaps only called in at the last moment to make the best of Compilation as it stands.

From the cataloguer's point of view, however, in regard to 
State-Papers, the Theory of Compilation pertains to the accurate and logical record of facts not only in reference to the immediate object of a special report or group of reports, but also in reference to the position which it shall afterwards occupy among all other works, as determined by the manner in which it is subsequently published.

For the furtherance of these two objects it is necessary that all compilation shall be based upon a certain Subject-Group arrangement specially designed to forward the mutual interests of both objects, to the detriment of neither.

It naturally follows that the Theory of Publication is the logical outcome of that of Compilatiox. It is that by which the world is best enabled to benefit by each printed record, taken separately or collectively with other works, and thus relates primarily to the ranner in which such printed records are issued.

Thus Publication is to Compilation as Compilation is to Facts, or, in other words, the object of Compilation is to make Facts accessible; the object of Publication is to make Records of Facts accessible.

A good illustration of the difference between the Publication systems of Departments and Cataloguers will be found in the case of reports relating to the annual Administration of Govern. ment Farms in India.

Thus in the North Western Provinces, we find the same reports styled in six different ways within a period of ten years, s.f., as the Reports of the-

I. Governmont Experimental Fam [Cawnporc].

2. ...............Experinzental Farn, Cawnpore.

3. Cawnpore Experimental Farm.

4. Cawnpord....................Farm.

5. Cawnpore Experimental Station.

6. Cawnpore Agricultural Station.

While in the case of other Provinces we find further four variations of title, e.g.,

7. Government Farm.

8. [District] Govermment Farm.

9. Experimestal Station.

10. Agriculitural Station.

Now it is apparent that each of the above title-phrases expresses accurately the contents of the report, and is, therefore, from a departmental view perfectly satisfactory. But from our point of view, ten different title-phrases for ten similar publica- 
tions is unsatisfactory, because if there were ten separate Provincial Catalogues, each compiled separately, and we wished to peruse these ten kindred reports, we might have much difficulty in finding them, as they might very possibly be indexed under ten different sub-headings instead of under one parallel subheading.

We want (before any title) two terms common to all the reports, which shall express accurately, simply and yet comprehensively (firstly), the Group to which they belong, and (secomdly) the special section of that Group, with due reference to other publications on the subject; and these terms we find in the words, AGRICULTURE and FARMS.

In illustration of the difference between the two theories of Compilation we may again refer to the subject of Indian History and Geography, and we shall find that while archrological and statistical surveys have been organised and separate archæological, historical, geographical and statistical reports issued, it has been found convenient or necessary, from departmental points of view, that in the absence of purely historical and gecgraphical Departments, any other Department whose duties permitted opportunities of observing the manners and customs of the people, of describing their history and noting geographical aspects of the country, should record that information, which should be entered in the report on the operations of that Departinent, whatever that Department be.

And thus it happens that we find a vast store of historical and geographical information in reports which were primarily written for other objects, and relating to such divers subjects as have been enumerated on page 135, commencing with the Census and ending with the reports of the Three Great Indian Surveys.

That such a system of Compilation should render it difficult or impossible to trace the required information is not surprising. Firstly. Because such information exists in so many unlikely and different places. Secondly. Because even if a reader knows that he will find his information in a certain report which is written mainly on another subject, it is impossible for him to know to what extent or at what intervals the subject has been included, so that he may have to skim the contents of twenty volumes and perhaps find fifty pages on his subject.in the twenty-first volume, or find no mention of it at all. Thirdly. He may find his one subject so closely worked into the other that at first sight it is indistinguishable from the other, and when recog- 
nised is very inextricable, and in all cases it is quite a chance whether he find any mention of the inclusion of his subject either in the table of contents or on the title-page.

The Cataloguer's theory of Compilation and Publication shows us the cause of the evil and its possible remedy or counteraction. The germ of it lies in the statement that-

Subject $A$ shall be reported upon in Report $A$, and shall be called Report $A$, and shall be bound up with Reports A.

It rests upon the truism that no information (which is supplied for the sake of future reference) should be entered in print except where we may most reasonably expect to find it, and the Theory of Publication further dictates the precise manner in which it should be published so as to enable us best to make use of it. This involves the details of separate issue, correct association in series, correct and comprehensive title and title-page, use of half-title-page to sectional reports, where necessary; use of appendices, proper tables of contents, the necessity of printing a report in the same year in which it is written, and the system of Binding according to Subjects.

We may make our meaning clearer, perhaps, by the following rule:-Given our country, the subjects of which are divided into twenty-six divisions $A-Z$, the composition of any report $A$ shall not be more (if it can be avoided) than is absolutely necessary to the special purpose which Division A should fulfil, if, by such composition, matter is included under Division $A$ which is wanting to complete the perfectness of another Division B, and that if it be necessary that the composition of Division A contain matter which is vital to the composition of another Division $B$, the arrangement of the composition of Division $A$ shall be such as shall enable Division $B$ to benefit by the matter referred to.

The above, of course, holds good in reference to any subdivisions of the several divisions. More technically this last statement may be further explained.

No Department A shall publish reports on Department B.

If it be necessary for Department $A$ to publish matter relating to Department $\mathrm{B}$, that information (if it have an exterior importance) shall be if possible conveyed in the form of a separate Appendix B, with separate half-title; being also noticed on the title-page to the whole report. Or, if it be absolutely necessary to work subject $B$ into subject $A$ throughout the report, subject $B$ shall be if possible entered in separate chapters or paragraphs, and shall 
Jikewise be noted in the table of contents and on the title-page, so that in either case a cross-reference may be made from $B$ to ( $B$ under $A$ ), thus showing the existence of the one and the connection between the two, and where it is considered inadvisable to make a cross-reference, we may often find a "Note" of great assistance.

Finally, as regards the Binding of our reports, the Theory of Publication demands that for a State-Paper Catalogue, no annual report $A$ shall be bound up with any other reports, except with reports $A$.

To sum up the main points of this paper, I have endeavoured to show:-

That "State-Papers" form, as a whole, a class distinct from all other printed works, and should therefore be treated in a manner peculiar to themselves. This renders it necessary that a StatePaper Catalogue should be exclusively devoted to State-Papers.

That since we have to contend with subjects and departments intricate in themselves, and with systems of Classification, Compilation, and Publication, which are often at variance with the principles which pertain to a successful Catalogue, we can neither detect the causes of our difficulties, nor remedy them in any degree, except we first enunciate clearly our own standard of principles according to our special object, by which to measure other systems.

That in regard to the actual compilation of a State-Paper Catalogue in its main points, it should be a Continwous Catalogue. It should possess full title-entries, entered under the countries to which the reports relate. (It is very common to find countries sub-ordinated to subjects.) And since Subjects are the only reliable factors with which we can deal, we take notice primarily of Subjects alone, only recognizing Departments when they tally with their Subjects, or when it is impossible to ignore them, and only grouping by $A$ uthors or Placs, in very rare instances.

Furthermore it has been pointed out, that having assigned our Subject-groups generally, and re-settled them in detail, showing the connection between them, we should endeavour to preserve the reports which relate to our Subject-groups, each under its respective group, and that when we find reports wholly or partly belonging to one group or more, inseparately attached to the reports of another group, we shall convey that information /either by Cross-references, or by Notes entered under the groups where such reports might ordinarily be searched for. 
Finally it has been shown to be essential that the binding of reports should tally with the cataloguing of them.

This is the sum of what I have now to say in introduction to the Theory of a State-Paper Catalogue, and now I will only remark in reference to the spirit in which this paper is written, that it is not for Librarians to dictate to Governments or to Departments the manner in which they should compile their reports, but since Librarians are called upon to deal with such publications - to arrange and catalogue them for the benefit of the State, no one will censure them for pointing out what are the principles which affect the success or failure of their efforts, or for showing that the principles of Departmental Publication of State-Papers may in many instances be with advantage assimilated with those which pertain to the successful cataloguing of the same.

F. B. F. Campbell.

APPENDIX.

EXAMPLES TO ILLUSTRATE SECTION ON SUBJECT GROUPING.

(a) Banitation:

Report, \&c.

-Dienacos.

Report, \&c

- Ecuitars Dranoh.

Report, \&c.

- Vital statiotios.

Report, \&c.

(b) Public Instruction:

Sar elro Bahoole ane Oalleses.

Ste der Dalveratts.

Report, \&c.

Bchools and Collezes.

Report, \&c.

Univeralty.

Report, \&c.

(c) Iight-Fonses.

Report, \&c.

Pablic Forles Department.

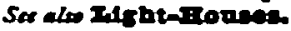

(d) Windmills.

Report, \&c. 
(d)

Publle Worke Dopartment. Irrisation as.

Report, \&c.

SPHCLL RIVERS AND CANAIS.

Reports on the Rivers and Canals specified below will bo found under Indin,-Rivers \&c.

2. 2urer.

O. zurer.

Q. Onank

D. Oenel.

Aen Aon to.

\section{Rallway Department.} Report, \&ce

SPRCIAL RAILWAYS.

Reports on the Railways specified below will be found under Indile. -Railways.

2. Zallwor.

C. zaniney.

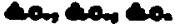

INDIA.

Rivers and Gannis.

This Sub-heading includes all Reports relating to the Irrigation or Navigation of specified Rivers or Canal, whether published by the Supreme Government or by the Local Governments.

D.2uver.

Report, \&c.

o. niver.

Report, \&c

O. Oenel.

Report, \&c.

D. Onnal co.

ans the

Inthe Depnrtuent.

Sos ato tander. Rnthas.

This Sub-beading includes all Reports relating to specified Railways, whether published by the Supreme Government or by the Local Governments.

2.2 ander.

Report, \&c.

O. 2nilus.

Report, \&c.

Note. - The character of the above type in the Appendix must not be accepted as final, but it is sufficient to illustrate the theory of Subject-Grouping. 